Article

\title{
Chinese Tourists' Barriers to Sharing Travel Photos in WeChat
}

\author{
Fangxuan (Sam) Li
}

New Zealand Tourism Research Institute, Auckland University of Technology, Auckland 1010, New Zealand; lifangxuan12345@126.com

Received: 28 December 2019; Accepted: 22 January 2020; Published: 24 January 2020

Abstract: Given the widespread availability of mobile internet and smart phones, photo-sharing on social networking services (SNS) has attracted a great deal of academic attention. Even though the number of photos shared on SNS is still increasing due to the increasing number of SNS users, some existing SNS users have now stopped sharing their travel photos on SNS. To fill the research gap, this paper explores Chinese tourists' barriers to sharing travel photos in WeChat. Based on 20 semi-structured interviews, this study identifies four barriers, including perceived risk, guanxi maintenance, personality, and disclosure. Given the importance of harmony in Chinese culture, this study also highlights the strong link between guanxi maintenance and Chinese visitors' willingness to share travel photos in WeChat. This paper discusses both the theoretical contribution and the practical implications of this study in the conclusion section.

Keywords: photo-sharing; Chinese tourists; barriers; WeChat; travel photos

\section{Introduction}

Photography has become a hot research topic in tourism studies recently [1-3]. "At the tourist level, photographs serve two important purposes; they document personal travel experiences and are used to share their personal tourism experiences with others. From an anthropological perspective, photographs taken during travel are in part driven by the desire to bring elements of personal tourism experiences home to share with others [4] and to relive their own experiences." [2] (p. 30). In fact, the widespread availability of mobile internet and smart phones has changed the traditional photo-taking and photo-sharing behaviors. The development of technology enables tourists to share their travel experiences with others by posting photos online during the visit instead of after the visit. Therefore, online photo-sharing, which is one of the most popular online activities, has attracted a great deal of academic attention $[5,6]$. It was found that online photo-sharing contributes to self-presentation, self-promotion, and impression formation effectively [7,8]. According to Marine-Roig [9] (p. 4), "new types of social media based on images/photographs have become increasingly important due to their usefulness and the ease with which users can share content on them." Given the close link between recreational travel and photography [10], photograph-based social media is becoming more and more popular for tourists. For example, Lo et al. [11] found that half of pleasure travelers posted their photographs online. The photographs posted online not only reflect visitors' travel experiences [11] but also influence potential visitors' perceptions of the travel destination's image [12]. Moreover, it was found that visitors who posted pictures on social medial are more likely to make a contribution to the destination's economic development through purchasing local souvenirs [13]. Given the importance of posted photos for destinations, one of the key tasks of destination marketing organizations (DMOs) is to ensure that the projected image is consistent with the long-term sustainability of a destination.

Even though digital photo-sharing is becoming increasingly popular, existing literature on digital photo-sharing reveals two problematic issues. Firstly, a review of the literature indicated that the 
majority of existing studies focus on Facebook and Instagram users. As Facebook and Instagram are blocked in China, a large number of Chinese social networking services (SNS) users are largely ignored by existing studies. For example, WeChat, which is the most used SNS in China, has one billion daily active users [14]. WeChat is a Chinese multi-purpose messaging social media and mobile payment app released in 2011 by Tencent. Compared to Facebook, "the distinctive characteristic of WeChat lies to the familiarity among users: most of the WeChat friends recognize each other in the reality." [15] (p. 30). WeChat users are able to share anything (texts, photos, and videos) with others in the WeChat moment. In addition to being a social network system, WeChat has been also described as China's "app for everything" and a "super app" because of its wide range of functions such as an e-commerce platform and marketing tool. These differentiate the differences between Chinese WeChat users and western SNS users. Secondly, though topics related to general photos are well examined by previous studies, travel photos in SNS are still under-researched [1,16]. Travel photos, as an important way to represent tourists' feelings and travel experiences, are largely ignored by existing literature. Though the number of shared travel photos on the social media is still on the rise, as shown by the increasing number of new WeChat users [17], some existing Chinese WeChat users (especially young generations) have now stopped sharing their travel photos in WeChat [18]. There is an urgent need for researchers to understand the reasons behind this new phenomenon. Theoretically, this study aims to explore Chinese tourists' barriers to sharing travel photos in WeChat to fill this research gap. This study also provides practical implications for WeChat operators to get rid of visitors' concerns surrounding sharing travel photos in WeChat.

\section{Literature Review}

\subsection{Photography in Tourism Studies}

Photography has been well examined by existing tourism studies from four perspectives. Firstly, the majority of previous studies focused on exploring tourists' photo-taking and sharing behaviors $[1,19,20]$. In terms of photo-taking, three hot topics were identified, including the content of travel photos [3,21], motivations for taking travel photos [22,23], and the factors influencing tourists' photo-taking behaviors [2,22]. Tourists are willing to record meaningful objectives or people during their visit through photos [3]. The content of travel photos was found to be influenced by their expectations [24], actual travel experience [25], and the intimate relationship between tourism and photo-taking [26]. This opinion related to the content of travel photos is supported by the circle of representation proposed by Jenkins [23] who argued that tourists are driven by the projected images to record their travel experience through photo-taking in the destinations. On one hand, tourists are able to share travel photos with their friends and relatives to prove their visit. On the other hand, the shared photos, as one form of image projection, are likely to begin the cycle again by influencing other people's perceived images of the destinations. However, the circle of representation was criticized by Garrod [27] (p. 346) who argued that "while in many respects the circle of representation may indeed be at work, in certain other respects it may not be. This suggests that a more finegrained and nuanced understanding of the circle of representation is required." Given the important role of shared photos in influencing tourists' perceived image of the destinations [28], the selection of the right photos to represent the destinations is becoming increasingly important for destination marketers in the era of digital marketing [29]. It seems impossible for a destination to achieve and maintain sustainability if a destination's image is wrong or misleading. From this perspective, the selection of the right photo to represent the destinations also contributes to the sustainable development of the destination. In addition to the content of travel photos and the motivations behind taking travel photos, previous studies found that tourists' photo-taking behaviors are influenced by travel frequency, tourists' demographic profile, generations, and cultures [2,22].

Secondly, the meanings of travel photos have been examined by previous studies [25,30]. According to Garlick [25], photographs played an important role in the production of memories and self-identity 
for photographers. The opinion was supported by Pan et al. [30] who argued that travel photos not only reflect visitors' inner feelings but also store visitors' travel experience.

Thirdly, photographs, as a source of data, have recently been used to understand tourists' cognitions, emotions, and behaviors [31-33]. Travel photos as a rich database were used by researchers to examine tourists' attitudes towards destinations from five perspectives, including how tourists behave, where, when, with whom, and why [31]. However, as the photographs were more often used as a source of data for qualitative studies than quantitative studies [31], a lack of gestalt (wholeness or unity) was identified based on a systematic review of the use of participant-generated image methods in social science research [32]. Therefore, canonical variate analysis is suggested to increase the reliability and validity of data analysis [32]. In terms of the focus of the research, Balomenou and Garrod [33] categorized empirical tourism research that used photographs as data into the following two groups: tourist behavior and experience, and destination image. They also categorized the research into three subgroups based on the use of research methods. The three subgroups include researcher-based content analysis of researcher-found photographs, photo-elicitation based on researcher-bound photographs, and photo-elicitation based on participant-generated photographs.

\subsection{SNS-Based Photo-Sharing}

A large number of SNS users expressed their feelings, thoughts, and emotions through photo-sharing on SNS [34]. SNS-based photo-sharing has been examined by existing studies from three perspectives. Firstly, the majority of previous studies focused on exploring the motivations of SNS-based photo-sharing [5,35]. Li [36] proposed eight main motivations behind photo-sharing on SNS after summarizing existing studies, including affection seeking, attention seeking, disclosure, entertainment, habitual pastime, information sharing, social influence, and social interaction. Li [36] further explored Chinese tourists' motivations for sharing travel photos in WeChat based on existing studies. Four motivations of sharing travel photos in WeChat were identified, including recognition and status, tourism information, enjoyment, and disclosure.

Secondly, previous studies examined the impact of demographic variables on SNS-based photo-sharing motivations and behaviors [2,36,37]. Dhir and Torsheim [37] explored gender and age differences in motivations for SNS-based photo-sharing. In terms of gender, they found that males are more willing to gain popularity and get more positive feedback (likes and comments) through sharing photos on SNS than females. The existence of gender differences in SNS-based photo-sharing gratifications is also identified by $\mathrm{Li}$ [36]. He found that females are more willing to share tourism information and enjoy sharing travel photos on SNS than males. In terms of age, Dhir and Torsheim's [37] study did not find any age differences in SNS-based photo-sharing motivations. However, Li's [36] study found age differences in Chinese tourists' motivations for sharing travel photos in WeChat. Li [36] found that middle-aged visitors (50-59 age group) are more likely to share tourism information than the young generations (18-29 age group). In addition to age and gender, Li [36] further found that SNS-based travel photo-sharing motivations are influenced by education level and income level. For example, it was found that participants who had no undergraduate qualification tend to share tourism information and enjoy sharing travel photos more than participants who had higher qualifications. It was also found that participants who had a higher level of monthly income (¥20,001 to 30,000 ) attached more importance to gaining social recognition and status through sharing travel photos in WeChat than participants who had a lower level of monthly income (less than $¥ 5000$ ). In addition to motivations, Prideaux et al. [2] further argued that SNS-based travel photo-sharing behaviors vary in generations and cultures based on a comparison of mainland Chinese and western visitors.

Thirdly, barriers to sharing photos on SNS were examined by previous studies [38,39]. The two main identified barriers are privacy and trust $[38,39]$. It was found that SNS users' attitudes towards privacy and trust vary in generations [39]. Even though young SNS users displayed a higher level of trust toward the SNS than old users, they were more concerned about the privacy of SNS-based photo sharing. A review of existing literature indicated that understanding the barriers to sharing photos on 
SNS is still very limited. What are the other barriers that influence visitors' intentions to share photos on SNS apart from privacy and trust? This paper aims to answer this question.

\section{Methodology}

As little is known about tourists' barriers to sharing travel photos in SNS, a constructivist grounded theory approach is deemed an appropriate way to conduct this research. A grounded theory approach is defined as a qualitative research method that uses a systematic set of processes to develop an inductively derived grounded theory about a phenomenon [40]. As suggested by Charmaz [41], the basic process of grounded theory include data collection and analysis, memo-writing, theoretical sampling, and saturation.

Semi-structured interviews were employed to obtain in-depth information [42] given the exploratory nature of this study. A total of 20 participants were interviewed between 1 October 2019 and 15 October 2019 (Table 1). There are two processes of recruiting interviewees through convenience and purposive sampling. Firstly, the author paper posted the purpose of this study and the intention to invite his friends to participate in this study in his WeChat moment. 32 people showed their interests to participate in this study within one week. Secondly, the author contacted the 32 friends who were willing to participant in this study. A total of 20 interviewees were finally selected on a purposive basis for embracing the socio-demographic diversity of WeChat users based on their gender, age, and education levels. Two selection criteria were used to recruit the interviewees. Firstly, the interviewees who had experience in sharing travel photos in WeChat were selected. Secondly, in order to understand Chinese tourists' barriers to sharing travel photos in WeChat, the interviewees who have decreased the frequency of sharing travel photos in WeChat or have stopped sharing travel photos in WeChat were selected finally.

As all the interviewees are friends of the author, the interviewees are more willing to share their ideas and opinions with him. To a large extent, the close relationship between the researcher and interviewees ensured the quality of interviews in the context of China. Open-ended questions were proposed, for example, what is your age? What is your education level? What is your frequency of travel in last 12 months? Where did you visit for your last trip? How many photos did you share in WeChat in last 12 months? Could you describe the reasons for uploading fewer photos than previous trips, please? What are the key barriers to sharing travel photos in WeChat and why? Then, interviewees were then actively asked for further explanations and clarifications on certain points uttered throughout the interviews [43]. The sample size can be justified by both the personal construct theory [44] and the social contribution theory $[45,46]$. As indicated by the personal construct theory, redundancy in comments was being achieved after about 15 interviews [47]. According to the social construction theory, the repetition and saturation responses tend to occur with approximately 15 respondents $[45,46]$. For this study, the interviewees did not provide any new information after conducting 16 interviews. Hence, data saturation was achieved after the 16th interview. Each interview lasted between 30 and 45 minutes. All interviews were conducted online, on WeChat, in Mandarin Chinese, and were audio-recorded with the consent of the interviewees. Chinese transcripts were used for data analysis to avoid missing data and distorting information at the transcription stage.

A content analysis was used to identify the key barriers to sharing travel photos in WeChat proposed by interviewees. According to Berg [48], a content analysis can be seen as a careful, detailed, systematic way to identify patterns, themes, biases, and meanings in social sciences. The data analysis followed Luborsky's [49] procedures. Firstly, in order to be familiar with the text, the author read the transcripts repeatedly to have an overview understanding of the whole text. Secondly, a thematic analysis was applied to code the transcript into various themes and subthemes based on literature review as well as the frequency of meaningful units. Table 2 shows the codes and categories that emerged from the texts. Thirdly, the results and supporting quotations were then translated into English after data analysis. According to Krippendorff [50], there are three distinct types of designs for reliability tests in a content analysis, including stability, reproducibility, and accuracy. In order to 
enhance the trustworthiness of the research, two strategies proposed by Creswell and Miller [51] were employed by this study. Firstly, member checking by taking the interview data and interpretations back to the participants was applied in this study to ensure the validity and credibility of the data analysis [52]. Five interviewees were asked whether they agreed with the proposed findings, which they did. Secondly, the results and supporting quotations were double checked by a Chinese-English linguist to minimize the possible inaccuracies of the translation after the member check.

Table 1. Profile of interviewees $(\mathrm{N}=20)$.

\begin{tabular}{|c|c|c|}
\hline & $\mathbf{N}$ & $\%$ \\
\hline \multicolumn{3}{|l|}{ Gender } \\
\hline Male & 9 & 45.0 \\
\hline Female & 11 & 55.0 \\
\hline \multicolumn{3}{|l|}{ Age } \\
\hline $20-25$ & 4 & 20.0 \\
\hline $26-30$ & 5 & 25.0 \\
\hline $31-35$ & 8 & 40.0 \\
\hline $36-40$ & 2 & 10.0 \\
\hline $41-45$ & 1 & 5.0 \\
\hline \multicolumn{3}{|l|}{ Education level } \\
\hline Under undergraduate & 2 & 10.0 \\
\hline Undergraduate & 10 & 50.0 \\
\hline Postgraduate & 8 & 40.0 \\
\hline \multicolumn{3}{|c|}{ Frequency of trips in last 12 months } \\
\hline Once a year & 5 & 25.0 \\
\hline 2-3 times & 12 & 60.0 \\
\hline 3-4 times & 2 & 10.0 \\
\hline 5 and more than 5 times & 1 & 5.0 \\
\hline \multicolumn{3}{|l|}{ Destination for last trip } \\
\hline Beijing & 4 & 20.0 \\
\hline Shanghai & 3 & 15.0 \\
\hline Japan & 2 & 10.0 \\
\hline Korea & 2 & 10.0 \\
\hline Australia & 2 & 10.0 \\
\hline USA & 1 & 5.0 \\
\hline Dali & 1 & 5.0 \\
\hline Xiamen & 1 & 5.0 \\
\hline Chengdu & 1 & 5.0 \\
\hline Dalian & 1 & 5.0 \\
\hline Hong Kong & 1 & 5.0 \\
\hline Macau & 1 & 5.0 \\
\hline \multicolumn{3}{|c|}{ Number of posted photos in last 12 months } \\
\hline Less than 10 & 5 & 25.0 \\
\hline $10-20$ & 7 & 35.0 \\
\hline $21-40$ & 3 & 15.0 \\
\hline $41-60$ & 1 & 5.0 \\
\hline $61-80$ & 2 & 10.0 \\
\hline 81-100 & 1 & 5.0 \\
\hline More than 100 & 1 & 5.0 \\
\hline
\end{tabular}


Table 2. The coding spectrum.

\begin{tabular}{|c|c|c|c|}
\hline Themes & Categories & Codes & $\begin{array}{l}\text { Number of } \\
\text { Respondents }\end{array}$ \\
\hline \multirow[t]{2}{*}{ Perceived risk } & Being tracked by others & Track my location, track my behavior & 11 \\
\hline & Leaking privacy & $\begin{array}{l}\text { A lack of privacy, safety and privacy of } \\
\text { photo-sharing, fake WeChat accounts }\end{array}$ & 16 \\
\hline \multirow{5}{*}{$\begin{array}{l}\text { Guanxi } \\
\text { maintenance }\end{array}$} & Creating a sense of envy & Jealous, a sense of envy, admire my life & 6 \\
\hline & Being disgusted by others & Less likes, less comments, less attention & 4 \\
\hline & Showing-off behavior & Showing off & 3 \\
\hline & Being put in the blocked list & Blocked list, blacklist & 5 \\
\hline & Getting negative comments & $\begin{array}{l}\text { Negative comments, get along with the } \\
\text { persons who post negative comments }\end{array}$ & 3 \\
\hline \multirow[t]{2}{*}{ Personality } & Unwilling to share & $\begin{array}{l}\text { Introvertive, unwilling to share, do not } \\
\text { want to share their private life }\end{array}$ & 3 \\
\hline & $\begin{array}{l}\text { Not interested in the use } \\
\text { of SNS }\end{array}$ & Not interesting, do not enjoy it & 2 \\
\hline \multirow{3}{*}{ Disclosure } & Criticized by parents & $\begin{array}{c}\text { Expensive, not necessary, a waste of } \\
\text { money and time }\end{array}$ & 5 \\
\hline & $\begin{array}{l}\text { Not a hard-working } \\
\text { employee }\end{array}$ & $\begin{array}{l}\text { Do not work hard, be criticized by } \\
\text { employee, a negative impact on career } \\
\text { development }\end{array}$ & 4 \\
\hline & $\begin{array}{l}\text { Being asked to purchase } \\
\text { goods for others }\end{array}$ & $\begin{array}{l}\text { Gifts, souvenirs, purchase goods for } \\
\text { friends, relatives, and colleagues }\end{array}$ & 5 \\
\hline
\end{tabular}

\section{Results}

Four barriers were identified by this study, including perceived risk, guanxi maintenance, personality, and disclosure. In the following section, the paper discusses how interviewees perceived these topics.

\subsection{Perceived Risk}

The majority of interviewees highlighted the potential risks of sharing travel photos in WeChat. Firstly, many interviewees perceived travel photo-sharing in WeChat as a dangerous action given the possibility of being tracked by other people. For example: "It is easy for other people to track my location and behavior through my shared photos in WeChat. Therefore, sharing travel photos in WeChat is very dangerous in my eyes. I do not really want to be tracked by other people" (Interviewee No. 12).

Secondly, a lack of privacy of sharing travel photos in WeChat is proposed by some interviewees. Travel photo-sharing is very private in these interviewees' eyes. They only would like to share the travel photos with their good friends and close relatives. However, a lack of privacy is becoming increasingly obvious for WeChat. As explained in the introduction part, WeChat is not only used for communicating or sharing information with friends and relatives but also for other purposes, such as e-commerce and marketing. Hence, as not all people in the list of WeChat contacts are the real friends of WeChat users, some interviewees are really concerned about the safety and privacy of sharing travel photos in WeChat now. One typical comment is "Some people in my WeChat are not my friends. I added them for some special needs, such as renting or purchasing products. It is very dangerous to let people who you are not familiar with to see my travel photos in WeChat from my perspective. However, it is also very embarrassing to set restrictions on accessing my WeChat moments for them if they know the news from other people." (Interviewee No. 14). Another interviewee similarly stated: "it is risky to share photos in WeChat now. I knew that some cheaters tend to create fake WeChat accounts by using your photos shared in WeChat. Then, they started to ask for money from your friends and relatives through this fake account. It has happened to one of my good friends before" (Interviewee No. 3). 
To sum up, one of the biggest barriers for Chinese tourists to share their travel photos in WeChat is the perceived risk. The main concerns include the possibility of being tracked by other people and a lack of privacy.

\subsection{Guanxi Maintenance}

Even though not all contacts in WeChat are friends, the majority of them are still friends. Therefore, many interviewees mentioned that travel photo-sharing in WeChat may have a negative impact on maintaining guanxi with other people. The content of guanxi, as a Chinese variant concept of social capital, is seen as networks and social resources [53]. Therefore, guanxi maintenance and development is crucial in Chinese society. The possible negative impacts of photo-sharing in WeChat on guanxi maintenance are explained below.

A harmonious relationship with other people is very important in Chinese culture. Some interviewees argued that the shared travel photos in WeChat caused them to create a sense of envy and sometimes harm their relationships with certain friends. To avoid this, these interviews are not willing to share their travel photos anymore. For example: "My WeChat contacts include my friends at different life stages, such as middle school classmates, undergraduate classmates, and my previous colleagues and current colleagues. Some of them are struggling with life and travel is a luxury consumption for them. Therefore, they may be jealous if I always share my travel photos in WeChat. It will make us in an embarrassing situation and harm our relationships" (Interviewee No.1).

Some interviewees are afraid of being disliked by others if they share a lot of travel photos in WeChat. One interviewee shared his personal experience with the authors: "I used to share a lot of my travel photos in WeChat before. I got a lot of likes and comments in the beginning. However, I realized that decreasing number of my WeChat friends pay attention to my travel photos later. I heard that I am disgusted by other people due to the intensive travel photo-sharing in WeChat. I really do not know the best frequency of travel-photo sharing in WeChat. I do care my relationships with my friends. Therefore, I did not share any travel photos in my WeChat for a year" (Interviewee No. 6).

Some interviewees also argued that travel photo-sharing in WeChat is likely to be seen as a showing-off behavior in others' eyes. Influenced by Confucianism, Chinese society has a strong value around modesty and humility. Chinese culture does not stand to show off personal honor, but to promote modesty. One interviewee stated: "Some people may feel that I am showing off if I share my travel photos in WeChat. That is really bad given the importance of modest and humility in Chinese culture. To avoid this, I do not really want to share any travel photos in my WeChat now" (Interviewee No. 5). Some interviewees further argued that they were put in the blocked list by some friends due to the intensive travel photo-sharing in WeChat. Guanxi (personal relationships) plays an important role in Chinese society; therefore, Chinese people are trying their best to protect their networks. For example: "I realized that many friends put me in the blocked list due to my intensive travel photo-sharing before. It took me a long time to build a good relationship with these friends; however, intensive travel photo-sharing made them put in the blocked list. Guanxi is so important in Chinese culture. I do not want to lose any friends anymore" (Interviewee No. 8). Some interviewees further highlighted the importance of face (mianzi) in Chinese culture. Simply speaking, face is defined as dignity or prestige. One of the worst things is to lose face in Chinese culture. Being put in the blocked list by friends is seen as losing face in some interviewees' eyes. According to Interviewee No. 10, "face is really important in China. Being put in the blocked list is face-losing from my perspective. Therefore, I stopped sharing travel photos in WeChat to avoid the uncomfortable situations."

In addition, some interviewees are afraid of getting negative comments from other people. One important motivation for WeChat users to share travel photos in WeChat is to get likes and positive comments. Inevitably, the interviewees sometimes got negative comments on their shared travel photos in WeChat from other people. The interviewees were angry with these negative comments. One interviewee stated: "I would like to share my travel experience and happiness with other people through shared travel photos in WeChat. However, the negative comments on my shared travel 
photos really ruin my mood" (Interviewee No. 4). Some interviewees further argued that they did not know how to deal with their relationship with the people who post negative comments. According to Interviewee No. 18, "The negative comments are very annoying. Frankly speaking, I really do not want how to get along with the people who post these negative comments. Should I argue with them or put them in the blacklist? I do not have a certain answer".

In summary, quotations show that Chinese people really care about guanxi maintenance and want to build a harmonious relationship with other people. It is found that the shared travel photos may create a sense of envy and get negative comments from other people. Therefore, they tend to decrease the frequency and number of travel photo-sharing in WeChat considering the possibility of being disgusted by others, being seen as a showing-off behavior in others' eyes, and being put in the blocked list by others.

\subsection{Personality}

Some interviewees argued that they are not willing to share travel photos in WeChat due to their personality attributes. Some interviewees are very introverted and do not want other people to know their private life; therefore, they seldom shared travel photos in their WeChat moments. For example: "I think that it is influenced by my personality. I really did not want other people to know my life since I was a kid. I only shared my stories or concerns with my parents and best friends face to face. I love travel and travel is an important part of my life. WeChat moment is a public area in my eyes. I do want to share anything related to my private life in a public area" (Interviewee No. 16).

Moreover, even though SNS is becoming increasing popular, some interviewees argued that they are not interested in the use of SNS. One interviewee stated: "Even though I am a WeChat user, I am not a fan of it. I only used it for business purposes such as communicating with my employers, colleagues and clients. I am a person who is not interested in sharing my life in SNS. Why should I force other people to know my life? That sounds strange for me" (Interviewee No. 7).

In brief, personality is a barrier to sharing travel photos in WeChat for some interviewees. It was found that some people feel that they do not want other people to know their private life through shared photos in WeChat, while some people are not interested in the use of SNS and sharing travel photos in WeChat.

\subsection{Disclosure}

Some interviewees pointed out that they did not want to share their travel experience with a group of people, including their parents, employers, and some friends, relatives, and colleagues. Some interviewees argued that travel is expensive and not necessary in their parents' eyes. In order to avoid getting pressure and negative comments from their parents, they are not willing to disclose their travel experience in WeChat. For example: "I liked to share my travel photos in WeChat 2 years ago. I always got comments from my parents immediately after they saw the photos in WeChat. They always criticized my travel. They told me that I need to save money for my future and travel is very luxurious. I do not want to argue with them and change their mind. To avoid letting them know my travel, I did not share my travel photos in WeChat" (Interviewee No. 2).

Apart from parents, some interviews stop sharing their travel photos in WeChat because of the possibility of being seen by their employers. One interviewee stated: "I would like to let my employer or group leaders feel that I am a hard-working person. Sharing travel photos in WeChat may let them feel that I am not mature. My focus is travel instead of work. This impression will have a negative impact on my career development." (Interviewee No. 9). Another interviewee similarly argued that "Working overtime is very common for my current job. Sometimes, I will refuse to work overtime if I do feel that I need a good rest. How does my boss think of me if he sees the travel photos in WeChat?" (Interviewee No. 15).

Some interviewees are concerned about being asked to purchase goods for friends, relatives, and colleagues if they share their travel photos in WeChat. One interviewee stated: "I was asked 
to purchase a lot of goods for my friends, relatives, and colleagues when they knew my overseas travel plan. I did spend much time on shopping for them. It is really annoying in terms of my tight travel schedule" (Interviewee No. 11). Another interviewee further highlighted the potential risks of purchasing goods for them: "Some of your friends, relatives and colleagues did not appreciate your efforts and time. Some of them may feel that you are earning their money if the price of the goods they asked you to purchase is higher than their expectations" (Interviewee No. 19).

In short, interviewees expressed their concerns about the pressure from their parents, employers, friends, relatives, and colleagues after sharing travel photos in WeChat.

\section{Discussion and Conclusions}

Given the increasing importance of user-generated photos for destination marketing, understanding tourists' attitudes towards travel photo-sharing on SNS is crucial. The shared travel photos not only influence potential tourists' perceptions of the destination image, but also influence their willingness to visit the destination. In terms of the economic contribution, sharing travel photos plays an important role in the sustainable development of the destination. Therefore, understanding tourists' barriers to sharing travel photos on SNS helps destination marketing operators promote the destination in the long term. Hence, this paper investigates Chinese tourists' barriers to sharing their travel photos in WeChat. The four barrier categories identified in this study are perceived risks, guanxi maintenance, personality, and disclosure (Figure 1). Firstly, the findings indicate that most interviewees perceived photo-sharing in WeChat as a risky behavior. The two main perceived risks proposed by interviewees are being tracked by other people and a lack of privacy. This finding was supported by existing studies, which found that two barriers to sharing photos on SNS are privacy and trust $[38,39]$. Secondly, as guanxi is seen as one of the most important success factors in Chinese society [54], guanxi building and maintenance is a crucial topic in China [55]. In this case, Chinese people tend to care about other people's feeling and build a good guanxi with other people. However, some interviewees argued that sharing travel photos in WeChat is seen as a showing-off behavior in some people's eyes. Therefore, the shared travel photos are likely to hurt other people's emotions if the photos create a sense of envy. Some interviewees further pointed out that travel photos shared in WeChat may also hurt their emotions, such as being disgusted by other people, being put in the blocked list, and being judged negatively. As harmony is a central concept in Chinese thought, maintaining a harmonious relationship with other people is crucial in Chinese society [56]. Therefore, these interviewees never shared their travel photos in WeChat to avoid these negative emotions and maintain a harmonious relationship with other people. Thirdly, personality was identified as a barrier to sharing travel photos in WeChat. It was found that some people are not willing to share their travel photos in WeChat, while some people are even not interested in the use of SNS. This finding was supported by Hughes et al. [57]. and Wang et al. [58], who found that there is a strong link between personality and the use of SNS. For example, Hughes et al. [57] found that personality is related to online socializing and information seeking. Similarly, Wang et al. [58] found that personality (shyness) enables us to predict the use of SNS. Finally, disclosure was identified as a barrier to sharing travel photos in WeChat. This finding helps explain the confirmatory factor analysis results of Chinese tourists' motivations for sharing travel photos in WeChat proposed by Li [36]. Even though disclosure is identified as an important motivation for travel photo-sharing in WeChat, the convergent validity and discriminant validity for this measurement do not exceed the acceptable level [36]. The study found that some interviewees are not willing to disclose their travel experience because of the possibility of being criticized by their parents, being seen as an employee that does not work hard, and being asked to purchase goods for other people. Overall, this study fills the research gap from two perspectives. Firstly, this research is one of the very first studies to explore tourists' barriers to sharing travel photos on SNS, especially in the context of Chinese tourists. Secondly, this study not only identified the common barriers for SNS users but also examined the influence of Chinese culture on tourists' intentions behind sharing travel photos in WeChat. 


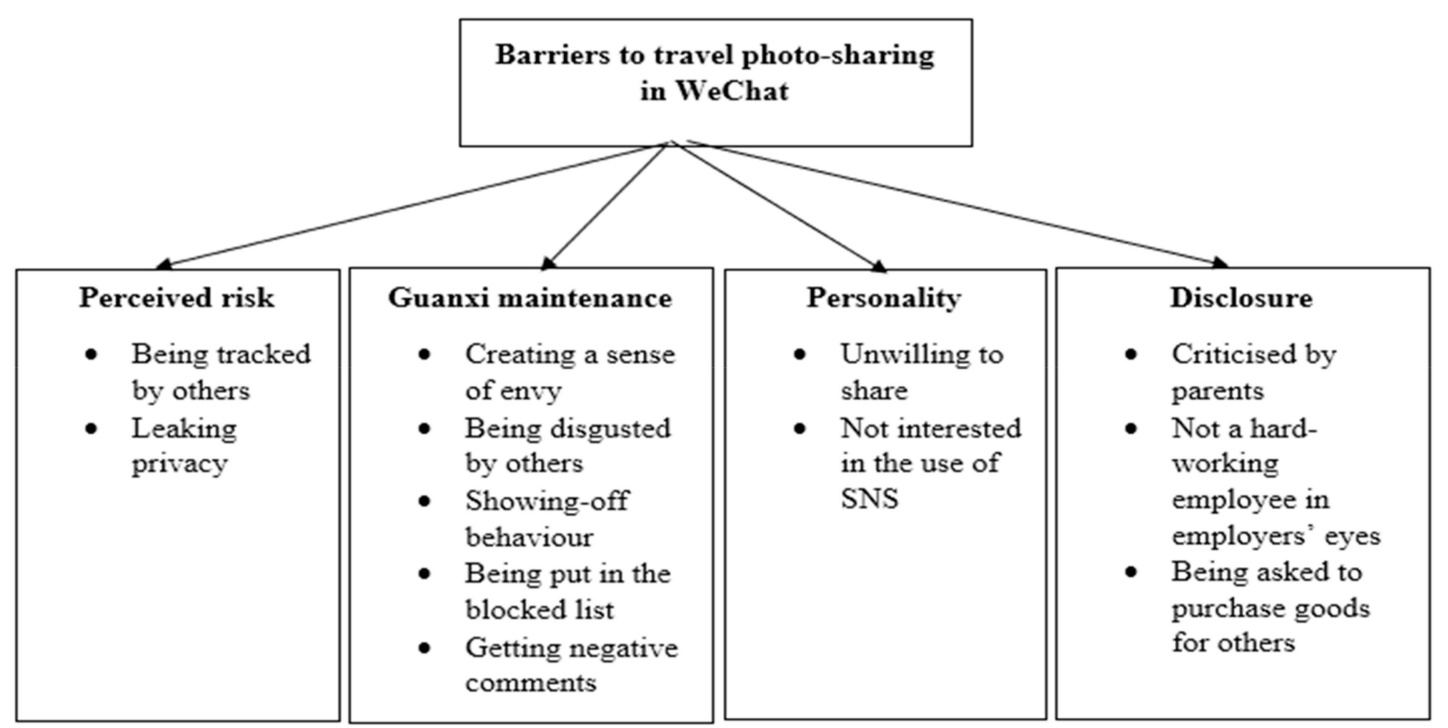

Figure 1. Barriers to travel photo-sharing in WeChat.

In addition to theoretical contributions, this paper also provided four valuable implications for WeChat operators based on the findings. Firstly, the study found that one big concern from interviewees is perceived risk. In order to get rid of this concern, WeChat should ask WeChat users to set restrictions on seeing their content shared in WeChat or hide their posts when adding new contacts in the beginning. It will be good for WeChat users to protect their privacy if they add someone who is not familiar with well. Moreover, as many interviewees are afraid of fake WeChat accounts by using their shared photos in WeChat, it will make WeChat users feel safe if WeChat allows users to set restrictions on downloading the shared photos from their WeChat moments. This measure helps to prevent WeChat friends who are not familiar with each other from downloading the uploaded photos from their respective WeChat moments. Secondly, considering the concerns related to guanxi maintenance and disclosure, the options for viewable by friends should be personalized. The four current options provided by WeChat include only 3 days of visible moments, only the last month of moments are visible, only last 6 months of moment are visible, and all moments are visible. It will be good for WeChat users to determine the visible days for different friends based on the relationships with their friends. Despite this, it is still hard to get rid of the concerns related to guanxi maintenance and disclosure for WeChat users. Therefore, WeChat operators would enable WeChat users to share their travel photos with themselves only. This means that WeChat users' shared travel photos can only be viewable by themselves, which not only not satisfies the needs of WeChat users but also gets rid of the concerns. Therefore, many slogans can be used to promote the use of WeChat by WeChat operators, such as "WeChat: A place for recording your own travel experience" and "WeChat: Your personal travel diary."

Despite the theoretical and practical contribution to existing studies in travel-photo sharing in SNS, there are still some limitations to this research. Firstly, the study explores the barriers to sharing travel photos in SNS from the perspective of Chinese visitors. Given the uniqueness of Chinese culture, some findings of this paper may not be applied to western visitors, such as guanxi maintenance. Secondly, as all the interviewees are friends of the author, it is a little bit hard to guarantee the heterogeneity of the interviews, which is one of the requirements of the interview. A diversity of interviewees should be approached for future research. Thirdly, this study pointed out that tourists' intentions behind sharing travel photos in WeChat is influenced by personality. Further research is required, particularly research using quantitative research methods, such as questionnaires, to explore the relationship between travel-photo sharing intentions and different types of personality, such as neuroticism, extraversion, openness-to-experience, agreeableness, conscientiousness, sociability, and need-for-cognition. Finally, the close link between demographic variables and the use of SNS was identified by previous studies; 
however, the influence of visitors' demographic variables, such as gender, age, and household income, on the intentions behind sharing travel photos are ignored by this study because of the nature of qualitative study. This topic needs to be examined by future studies. Despite the limitations of this research, this exploratory study still lays a good foundation for future research.

Funding: This research received no external funding.

Conflicts of Interest: The author declares no conflict of interest.

\section{References}

1. Konijn, E.; Sluimer, N.; Mitas, O. Click to share: Patterns in tourist photography and sharing. Int. J. Tour. Res. 2016, 18, 525-535. [CrossRef]

2. Prideaux, B.; Lee, L.Y.-S.; Tsang, N. A comparison of photo-taking and online-sharing behaviors of mainland Chinese and Western theme park visitors based on generation membership. J. Vacat. Market. 2018, 24, $29-43$. [CrossRef]

3. Lyu, S.O. Travel selfies on social media as objectified self-presentation. Tour. Manag. 2016, 54, $185-195$. [CrossRef]

4. Graburn, N.H.H. The anthropology of tourism. Ann. Tour. Res. 1983, 10, 9-33. [CrossRef]

5. Malik, A.; Dhir, A.; Nieminen, M. Uses and gratifications of digital photo sharing on Facebook. Telemat. Inform. 2016, 33, 129-138. [CrossRef]

6. Pai, P.; Arnott, D.C. User adoption of social networking sites: Eliciting uses and gratifications through a means-end approach. Comput. Hum. Behav. 2013, 29, 1039-1053. [CrossRef]

7. Eftekhar, A.; Fullwood, C.; Morris, N. Capturing personality from Facebook photos and photo-related activities: How much exposure do you need? Comput. Hum. Behav. 2014, 37, 162-170. [CrossRef]

8. Scott, G.G.; Hand, C.J. Motivation determines Facebook viewing strategy: An eye movement analysis. Comput. Hum. Behav. 2016, 56, 267-280. [CrossRef]

9. Marine-Roig, E.; Martin-Fuentes, E.; Daries-Ramon, N. User-generated social media events in tourism. Sustainability 2017, 9, 2250. [CrossRef]

10. Markwell, K.W. Dimensions of photography in a nature-based tour. Ann. Tour. Res. 1997, 24, 131-155. [CrossRef]

11. Lo, I.S.; McKercher, B.; Lo, A.; Cheung, C.; Law, R. Tourism and online photography. Tour. Manag. 2011, 32, 725-731. [CrossRef]

12. Kim, H.; Stepchenkova, S. Effect of tourist photographs on attitudes towards destination: Manifest and latent content. Tour. Manag. 2015, 49, 29-41. [CrossRef]

13. Bynum Boley, B.; Magnini, V.P.; Tuten, T.L. Social media picture posting and souvenir purchasing behavior: Some initial findings. Tour. Manag. 2013, 37, 27-30. [CrossRef]

14. Business of Apps. WeChat Revenue and Usage Statistics. Available online: https://www.businessofapps. com/data/wechat-statistics/ (accessed on 22 December 2019).

15. Gan, C. Understanding WeChat users' liking behavior: An empirical study in China. Comput. Hum. Behav. 2017, 68, 30-39. [CrossRef]

16. Wang, S.; Kirillova, K.; Lehto, X. Travelers' food experience sharing on social network sites. J. Travel. Tour. Market. 2017, 34, 680-693. [CrossRef]

17. Peng, Y. Sharing food photographs on social media: Performative Xiaozi lifestyle in Young, middle-class Chinese urbanites' WeChat 'Moments'. Soc. Identities 2019, 25, 269-287. [CrossRef]

18. South China Morning Post. Chinese Teens are Shying Away from Posting about Their Lives on WeChat to Avoid Prying Parents. Available online: https://www.scmp.com/tech/apps-social/article/3024156/chineseteens-are-shying-away-posting-about-their-lives-wechat (accessed on 22 December 2019).

19. Li, M.; Sharpley, R.; Gammon, S. Towards an understanding of Chinese tourist photography: Evidence from the UK. Curr. Issues in Tour. 2019, 22, 505-521. [CrossRef]

20. Zhao, Z.; Zhu, M.; Hao, X. Share the Gaze: Representation of destination image on the Chinese social platform WeChat Moments. J. Travel. Tour. Market. 2018, 35, 726-739. [CrossRef]

21. Van House, N.A. Personal photography, digital technologies and the uses of the visual. Vis. Stud. 2011, 26, 125-134. [CrossRef] 
22. Chalfen, R.M. Photograph's role in tourism: Some unexplored relationships. Ann. Tour. Res. 1979, 6, $435-447$. [CrossRef]

23. Jenkins, O. Photography and travel brochures: The circle of representation. Tour. Geogr. 2003, 5, 305-328. [CrossRef]

24. Feighery, W. Tourism, stock photography and surveillance: A Foucauldian interpretation. J. Tour. Cult. Chang. 2009, 7, 161-178. [CrossRef]

25. Garlick, S. Revealing the unseen: Tourism, art and photography. Cult. Stud. 2002, 16, 289-305. [CrossRef]

26. Urry, J. The Tourist Gaze: Leisure and Travel in Contemporary Societies, Theory, Culture E Society; Sage: London, UK, 1990.

27. Garrod, B. Understanding the relationship between tourism destination imagery and tourist photography. J. Travel Res. 2009, 47, 346-358. [CrossRef]

28. Galí, N.; Donaire, J.A. Tourists taking photographs: The long tail in tourists' perceived image of Barcelona. Curr. Issues in Tour. 2015, 18, 893-902. [CrossRef]

29. Deng, N.; Li, X. Feeling a destination through the "right" photos: A machine learning model for DMOs' photo selection. Tour. Manag. 2018, 65, 267-278. [CrossRef]

30. Pan, S.; Lee, J.; Tsai, H. Travel photos: Motivations, image dimensions, and affective qualities of places. Tour. Manag. 2014, 40, 59-69. [CrossRef]

31. Balomenou, N.; Garrod, B.; Georgiadou, A. Making sense of tourists' photographs using canonical variate analysis. Tour. Manag. 2017, 61, 173-179. [CrossRef]

32. Balomenou, N.; Garrod, B. A review of participant-generated image methods in the social sciences. J. Mixed. Methods. Res. 2015, 10, 335-351. [CrossRef]

33. Balomenou, N.; Garrod, B. Photographs in tourism research: Prejudice, power, performance and participant-generated images. Tour. Manag. 2019, 70, 201-217. [CrossRef]

34. Mendelson, A.; Papacharissi, Z. Look at us; Collective Narcissism in College Student Facebook Photo Galleries. The Networked Self: Identity Community and Culture of Social Networking Sites; Routledge: Abingdon-on-Thames, UK, 2010.

35. Urista, M.A.; Dong, Q.; Day, K.D. Explaining why young adults use MySpace and Facebook through uses and gratifications theory. Hum. Commun. 2009, 12, 215-229.

36. Li, F. Understanding Chinese tourists' motivations of sharing travel photos in WeChat. Tour. Manag. Perspect. 2020, 33, 100584. [CrossRef]

37. Dhir, A.; Torsheim, T. Age and gender differences in photo tagging gratifications. Comput. Hum. Behav. 2016, 63, 630-638. [CrossRef]

38. Malik, A.; Hiekkanen, K.; Dhir, A.; Nieminen, M. Impact of privacy, trust and user activity on intentions to share Facebook photos. J. Inf. Commun. Eth. Soc. 2016, 14, 364-382. [CrossRef]

39. Malik, A.; Hiekkanen, K.; Nieminen, M. Privacy and trust in Facebook photo sharing: Age and gender differences. Program 2016, 50, 462-480. [CrossRef]

40. Pandit, N.R. The creation of theory: A recent application of the grounded theory method. Qual. Rep. 1996, 2, 1-15.

41. Charmaz, K. Constructing Grounded Theory: A Practical Guide through Qualitative Research; Sage: London, UK, 2006.

42. Yin, R.K. Case Study Research: Design and Methods; Sage: Thousand Oaks, CA, USA, 2008.

43. Qi, H.X.; Smith, K.A.; Yeoman, I.; Xie, J.J. Analysis of student volunteer experience at conferences: An exploratory study of the First World Conference on Tourism for Development. In Proceedings of the Asia Pacific Tourism Association (APTA) 2017 Annual Conference, Busan, South Korea, 18-21 June 2017.

44. Kelly, G.A. The Psychology of Personal Constructs; Norton: New York, NY, USA, 1955.

45. Kelly, G.A. A Theory of Personality: The Psychology of Personal Constructs; Norton: New York, NY, USA, 1963.

46. Pike, S. Destination positioning opportunities using personal values: Elicited through the Repertory Test with Laddering Analysis. Tour. Manag. 2012, 33, 1281-1285. [CrossRef]

47. Armstrong, D.J. Causal Mapping: A Discussion and Demonstration; Idea Group: Hershey, PA, USA, 2005; pp. 20-45.

48. Berg, B.L. An Introduction to Content Analysis; Allyn and Bacon: Boston, MA, USA, 2001; pp. $238-267$.

49. Luborsky, M. The Identification and Analysis of Themes and Patterns; Sage: Thousand Oaks, CA, USA, 1994; pp. 189-210. 
50. Krippendorff, K. Content Analysis: An Introduction to its Methodology; Sage: Thousand Oaks, CA, USA, 1980.

51. Creswell, J.W.; Miller, D.L. Determining validity in qualitative inquiry. Theory into Pract. 2000, 39, $124-130$. [CrossRef]

52. Cho, J.; Trent, A. Validity in qualitative research revisited. Qual. Res. 2006, 6, 319-340. [CrossRef]

53. Liu, D.; Morgan, W.J. Students' decision-making about postgraduate education at G University in China: The main factors and the role of family and of Teachers. Asia-Pac. Edu. Res. 2016, 25, 325-335. [CrossRef]

54. Chang, E.-C.; Chou, T.-J.; Huang, C.; Wang, X. The categories, rules, and demonstrations of guanxi in Chinese society. J. Bus. Bus. Market. 2016, 23, 311-325. [CrossRef]

55. Guo, Y.; Rammal, H.G.; Benson, J.; Zhu, Y.; Dowling, P.J. Interpersonal relations in China: Expatriates' perspective on the development and use of guanxi. Int. Bus. Rev. 2018, 27, 455-464. [CrossRef]

56. Li, C. The philosophy of harmony in classical Confucianism. Philos. Compass. 2008, 3, 423-435. [CrossRef]

57. Hughes, D.J.; Rowe, M.; Batey, M.; Lee, A. A tale of two sites: Twitter vs. Facebook and the personality predictors of social media usage. Comput. Hum. Behav. 2012, 28, 561-569. [CrossRef]

58. Wang, J.-L.; Jackson, L.A.; Wang, H.-Z.; Gaskin, J. Predicting Social Networking Site (SNS) use: Personality, attitudes, motivation and Internet self-efficacy. Personal. Individ. Differ. 2015, 80, 119-124. [CrossRef]

(C) 2020 by the author. Licensee MDPI, Basel, Switzerland. This article is an open access article distributed under the terms and conditions of the Creative Commons Attribution (CC BY) license (http://creativecommons.org/licenses/by/4.0/). 